\title{
Participation of a $\beta$-Adrenergic System in Dopamine Stimulation of Respiration in Isolated Rat Brown Adipocytes
}

\author{
Takashi IDE* and Michihiro SUGANo \\ Laboratory of Nutrition Chemistry, Kyushu University School of Agriculture, \\ 46-09, Fukuoka 812, Japan \\ Received July 10, 1987
}

\begin{abstract}
The characteristics of dopamine- and norepinephrine-stimulation of respiration in isolated rat brown adipocytes were compared. Although both dopamine and norepinephrine rapidly stimulated the respiration and lipolysis of isolated cells, much higher concentrations of dopamine compared to norepinephrine were required to cause the same extent of response. Antagonists of the dopamine receptor (haloperidol) and of the $\beta$-adrenoreceptor (propranolol) suppressed respiration that was stimulated by either dopamine $(50 \mu \mathrm{M})$ or norepinephrine $(0.2 \mu \mathrm{M})$. Unexpectedly, dopaminestimulated respiration was completely inhibited by the $\beta$-adrenergic blocker at a concentration far lower than that required to inhibit norepinephrine-stimulated respiration. Both catecholamines added at concentrations of a large excess to stimulate respiration overcame the inhibitory action of propranolol but not of haloperidol. An agonist of the dopamine receptor, apomorphine $(50 \mu \mathrm{M})$, failed to stimulate the respiration of brown adipocytes. These results indicate that dopamine at a high concentration stimulates the respiration of brown adipocytes primarily through interaction with the $\beta$-adrenoreceptor, but not with the dopamine receptor.
\end{abstract}

Brown adipose tissue is the major site of heat production during cold exposure (nonshivering thermogenesis) or after overeating (diet-induced thermogenesis) in several animal species. ${ }^{1 \sim 4)}$ Overwhelming evidence has indicated that norepinephrine released from sympathetic nerve activated brown adipose tissue to produce the heat through interaction with the $\beta$-adrenoreceptor ${ }^{5,6)}$ and possibly with the $\alpha$-adrenoreceptor. ${ }^{7 \sim 9)}$ On the other hand, Rothwell and her colleagues ${ }^{10)}$ found that dopamine and norepinephrine were equally effective for inducing thermogenesis when they were administered subctaneously to rats. The administration of pimozide, an antagonist of dopamine, completely removed an increase in heat production after the dopamine treatment. They also demonstrated the release of dopamine from the sympathetic nerves innervated in brown adipose tissue. Thus, there is a possibility that dopamine in addition to norepinephrine plays a role in regulating the heat production in brown adipose tissue through interaction with the specific dopamine receptor. However, as dopamine is the precursor of functional catecholamines that include norephrine, the results obtained in an intact animal are indeed hard to evaluate. In this context, some characteristics of dopamine-mediated thermogenesis were investigated in isolated brown adipocytes from rats in the present study.

\section{MATERIALS AND METHODS}

Isolation of brown adipocytes. Male Sprague-Dawley rats (Seiwa Experimental Animals, Fukuoka) at ages of 7 to 9 weeks and weighing $250 \sim 350 \mathrm{~g}$ were used throughout the present study. The animals were housed in an airconditioned room $\left(22 \sim 24^{\circ} \mathrm{C}\right.$ with lights on from 8:00 a.m. to 8:00 p.m.) with free access to a commercial diet (type NMF, Oriental Yeast Co., Tokyo). The rats were lightly anesthetized with diethylether and blood was withdrawn

* Present address: Laboratory of Nutrition Chemistry, National Food Research Institute, Ministry of Agriculture, Forestry and Fisheries, 2-1-2 Kannondai, Yatabe, Tsukuba, Ibaraki 305, Japan. 
from the abdominal aorta. Brown adipose tissues located in the interscapular, cervical and axillary regions were dissected out. Routinely, the tissue from 2 rats was pooled. Brown adipocytes were isolated by the method of Bukowiecki et al. ${ }^{5)}$ with a slight modification as subsequently described. The tissue (1.5 to $2.5 \mathrm{~g}$ ) was finely minced with scissors and a portion of the minced tissue $(20 \sim 30 \mathrm{mg})$ was homogenized in $2 \mathrm{ml}$ of $0.25 \mathrm{M}$ sucrose containing $20 \mathrm{~mm} N$-tris(hydroxymethyl)methyl-2-aminoethanesulfonic acid (TES), at $\mathrm{pH} 7.2$ for the measurement of cytochrome $c$ oxidase activity. The remaining tissue was placed into $30 \mathrm{ml}$ plastic vial, and $2 \mathrm{ml}$ of modified Krebs-Ringer bicarbonate buffer ( $\mathrm{pH}$ 7.4) containing $5 \mathrm{mg}$ collagenase was added, before digesting at $37^{\circ} \mathrm{C}$ in a shaking water bath. The modified Krebs-Ringer bicarbonate buffer included in $\mathrm{mM}: \mathrm{NaCl}, 118.4 ; \mathrm{KCl}$, 4.7; $\mathrm{CaCl}_{2}, 2.5 ; \mathrm{MgSO}_{4}, 1.5 ; \mathrm{NaHCO}_{3}, 24.6 ; \mathrm{K}_{2} \mathrm{HPO}_{4}, 1.5$; $N$-2-hydroxylethylpiperanine- $N^{\prime}$-2-ethanesulfonic acid (HEPES), 30; glucose, 2.7; and fatty acid-free albumin $(1 \%)$. During the digestion period, the vial was shaken vigorously by hand for about $15 \mathrm{sec}$ at $1 \mathrm{~min}$ intervals. After $15 \mathrm{~min}$ of the digestion period, $15 \sim 20 \mathrm{ml}$ of the bicarbonate buffer was added, and the mixture was filtered through two layers of gauze into a plastic tube. The brown adipocytes were allowed to float to the top of the tube at room temperature for about $30 \mathrm{~min}$. The cells were harvested and washed 3 times with the bicarbonate buffer as already described. During the washing procedure, the concentration of albumin was adjusted to $0.4 \%$. The washed cells were finally suspended in 3 to $4 \mathrm{ml}$ of the buffer containing $0.4 \%$ albumin, and the cytochrome $c$ oxidase activity was measured in an aliquot of the suspension

Measurement of oxygen consumption by isolated brown adipocytes. The oxygen consumption of the cell suspension was measured at $37^{\circ} \mathrm{C}$ in a water-jacketed chamber at a final volume of $1.5 \mathrm{ml}$. The oxygen concentration in the suspension was continously monitored polarographically using a Clark-style oxygen electrode (Yellow Spring Instrument, Yellow Springs, $\mathrm{OH}$ ) in the modified KrebsRinger bicarbonate buffer. The composition of the buffer was similar to that used for the isolation of adipocytes, but contained $10 \mathrm{~mm}$ fructose and $1 \mathrm{~mm}$ pyruvate, the albumin and glucose concentrations being adjusted to $0.4 \%$ and $10 \mathrm{~mm}$, respectively.

Determination of cytochrome $c$ oxidase activity. Cytochrome $c$ oxidase activity was measured spectrophotometrically ${ }^{11)}$ in the brown adipose tissue homogenate and in the isolated cell suspension for estimating the amount of cells used for the measurement of oxygen consumption. The respiratory activity of the isolated cells was calculated and expressed on the basis of the original wet tissue weight using the following equation ${ }^{5)}$ :
Respiratory activity (nmol/mg tissue)

$$
\begin{aligned}
& =\text { Oxygen consumption }(\mathrm{nmol}) \\
& \text { Cytochrome } c \text { oxidase activity in } \\
& \mathrm{mg} \text { of original wet tissue }\left(\mathrm{sec}^{-1}\right) \\
& \text { Cytochrome } c \text { oxidase activity in } \\
& \text { the cell suspension }\left(\mathrm{sec}^{-1}\right)
\end{aligned}
$$

Cytochrome $c$ oxidase activity expressed as the first-order rate constant $\left(\mathrm{sec}^{-1}\right)$ was calculated from the time course curve of the enzyme reaction. ${ }^{11)}$

Materials. (-)-Norepinephrine bitartrate salt, haloperidol and apomorphine hydrochloride were purchased from Sigma Chemical Co., St. Louis, MO. DL-Propranolol hydrochloride, dopamine hydrochloride and phenoxybenzamine hydrochloride were from Nakarai Chemical Co., Kyoto. Collagenase from Closridium histolyticum was a product of Wako Pure Chemical Industries, Osaka, fatty acid-free bovine serum albumin was from Miles Scientific, Naperville, IL.

\section{RESULTS}

The recovery of brown adipocytes as estimated from the activity of cytochrome $c$ oxidase ranged from 3 to $5 \%$, these values being comparable to those reported elsewhere. ${ }^{5)}$ Staining the cell preparation by trypan blue showed that more than $90 \%$ of the cells was viable. The respiratory activity of brown fat cells has been frequently expressed on the basis of the cell number. However, cell number counting was found to be rather tedious, time consuming and sometimes difficult for distinguishing between brown adipocytes and the contaminating fat droplets from broken cells. In this context, the respiratory activity is expressed in the present study on the basis of wet tissue weight calculated by comparing the cytochrome $c$ oxidase activity in the cell suspension with that in the original tissue. Bukowiecki et $a .^{5)}$ reported that the maximal respiratory activity of brown adipocytes stimulated by norepinephrine was $410 \mathrm{nmol}$ oxygen consumed $/ \mathrm{min} / \mathrm{million}$ cells. They also reported that $1 \mathrm{mg}$ of interscapular brown adipose tissue contained $7.4 \times 10^{4}$ adipocytes. Thus, the maximal respiratory activity of brown adipose tissue is calculated to be $30 \mathrm{nmol}$ oxygen $/ \mathrm{min} / \mathrm{mg}$ tissue. This value approxi- 


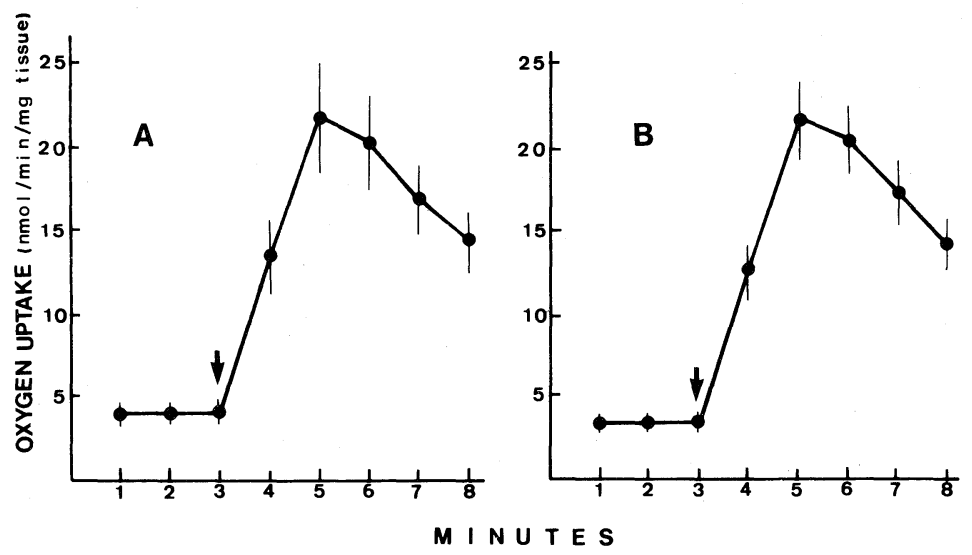

FIG. 1. Time Course of the Change in Rate of Oxygen Consumption by Brown Adipocytes after Stimulation by Dopamine (A) and Norepinephrine (B).

The oxygen uptake by isolated brown adipocytes was continuously monitored polarographically as described in Materials AND Methods. The rate of oxygen uptake was calculated over every 1 minute. Each value represents the mean $\pm \mathrm{SE}$ of 21 and 29 different cell preparations for dopamine- and norepinephrinestimulated cells, respectively. Arrows indicate the times when the dopamine (50 $\mu \mathrm{M})$ or norepinephrine $(0.2 \mu \mathrm{M})$ was added.

mated to those reported here of $22 \sim 32 \mathrm{nmol}$ oxygen $/ \mathrm{min} / \mathrm{mg}$ tissue.

As shown in Fig. 1, $50 \mu \mathrm{M}$ of dopamine and $0.2 \mu \mathrm{M}$ norepinephrine stimulated the oxygen uptake by isolated brown adipocytes. The respiration rate rapidly increased and attained a peak at around 2 min after the addition of catecholamines, then gradually decreased. Similar contours for these responses have been observed in norepinephrine-treated brown adipocytes. $^{12 \sim 14)}$ As the respiration rate between 1.5 and $3 \mathrm{~min}$ after the addition of catecholamines was found to be almost maximal and linear in both cases, the rate calculated over this time interval was taken as the catecholamine-stimulated respiration rate in the subsequent studies.

An enhancement of lipolysis by norepinephrine is the first event to induce a catecholamine-mediated increase in brown adipocyte respiration. ${ }^{1,15)}$ In a preliminary experiment, two different cell preparations were incubated with dopamine $(50 \mu \mathrm{M})$ and norepinephrine $(0.2 \mu \mathrm{M})$, and the release of glycerol was determined enzymatically. ${ }^{16)}$ Dopamine apparently compared to norepinephrine, but less effectively stimulated glycerol release $(24$,
48 and $83 \mathrm{nmol} / 15 \mathrm{~min} / \mathrm{mg}$ tissue for the cells incubated without catecholamine, with dopamine and with norepinephrine, respectively). Thus, it seems that these catecholamines may share the same mechanism for stimulating the thermogenesis by brown adipocytes.

A relatively high concentration of dopamine was required to stimulate the oxygen uptake by the cells (Fig. 2). A detectable increase in the rate of oxygen consumption above the basal value was first noted with $5 \mu \mathrm{m}$ dopamine, and the $50 \mu \mathrm{M}$ concentration was required to yield maximal respiration (Fig. 2A). However, norepinephrine as low as $0.002 \mu \mathrm{M}$ detectably stimulated oxygen uptake, and the respiration rate reached a plateau at a concentration of $0.05 \mu \mathrm{M}$ (Fig. 2B). The concentration of catecholamines to induce the half-maximum response was $18 \mu \mathrm{M}$ for dopamine and $0.008 \mu \mathrm{M}$ for norepinephrine. Thus, norepinephrine was approximately 2,000 times more potent than dopamine as a stimulant for brown adipocyte thermogenesis.

In order to clarify which of the catecholamine receptors is responsible for dopamine stimulation, the respiratory responses of 


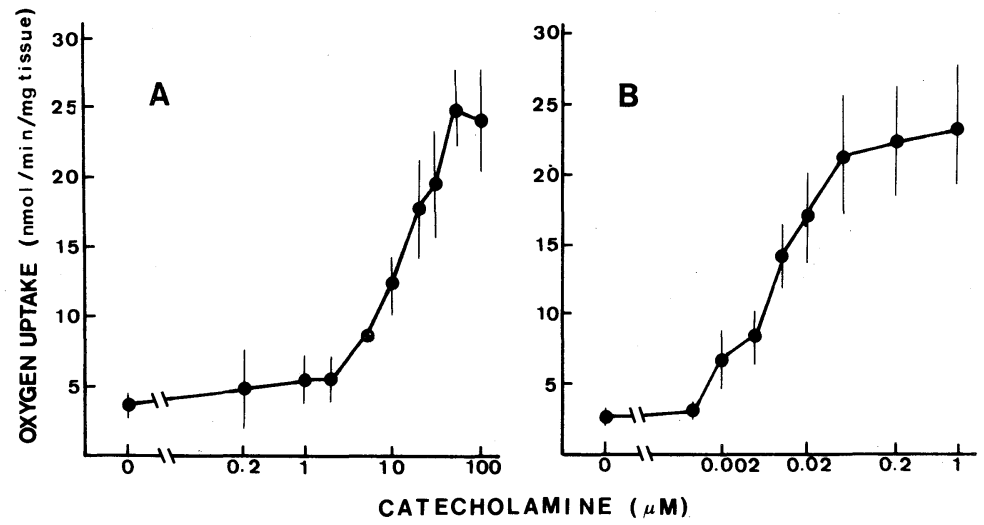

FIG. 2. Respiratory Response of Brown Adipocytes to Different Concentrations of Dopamine (A) and Norepinephrine (B).

The rate of oxygen uptake by isolated brown adipocytes was determined in the presence of various concentration of catecholamines. The maximal rate of oxygen uptake by isolated adipocytes was attained 1.5 to $3 \mathrm{~min}$ after the addition of catecholamines. The rate calculated over the time interval is presented in this figure, each value representing the mean $\pm \mathrm{SE}$ of 3 to 6 different cell preparations.

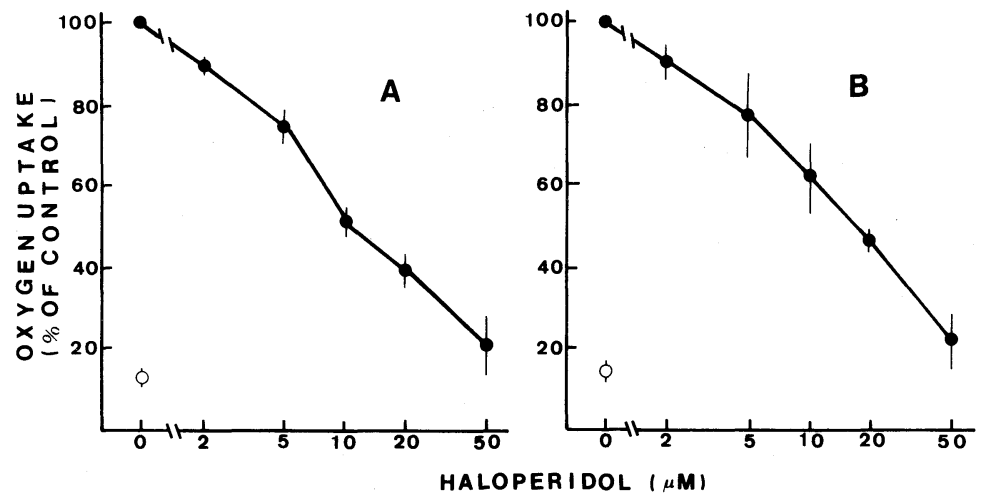

FIG. 3. Respiratory Response to the Dopaminergic Antagonist, Haloperdol, of Brown Adipocytes Stimulated by Dopamine (A) and Norepinephrine (B).

The rate of oxygen uptake by isolated brown adipocytes stimulated by dopamine $(50 \mu \mathrm{M})$ or norepinephrine $(0.2 \mathrm{M})$ was determined in the presence of various concentrations of haloperidol. The catecholamines and various amounts of the antagonist were simulteneously added in the respiratory chamber. The maximal respiration rate over the time interval between 1.5 to $3 \mathrm{~min}$ after the addition of the drugs was calculated. Data are presented as a percentage of the value obtained in the absence of the antagonist, each value representing the mean $\pm \mathrm{SE}$ of 4 to 5 different cell preparations. Open circles indicate the basal rate of oxygen uptake measured in the absence of catecholamines.

brown adipocytes to catecholamine antagonists and agonists were examined in the following experiments.

Haloperidol, a dopaminergic antagonist, ${ }^{17,18)}$ effectively reduced the dopaminestimulated $(50 \mu \mathrm{M})$ respiration of brown adipocytes (Fig. 3A). The respiration rate progressively reduced as the concentration of the drug increased, and the value reached nearly to the basal level at the concentration of the $50 \mu \mathrm{M}$ blocker. Unexpectedly, haloperidol also inhibited the respiration stimulated by $0.2 \mu \mathrm{M}$ norepinephrine (Fig. 3B). Thus, this blocker could not be regarded as a compound specific to the dopamine receptor, at least in terms of an inhibitory potency to the respiration of 


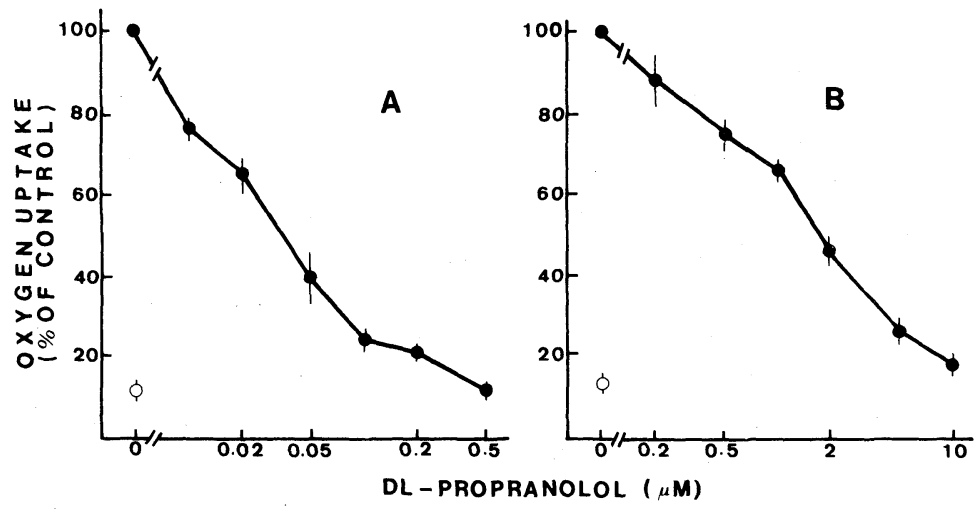

FIG. 4. Respiratory Response to the $\beta$-Adrenergic Antagonist, Propranolol, of Brown Adipocytes Stimulated by Dopamine (A) and Norepinephrine (B).

The rate of oxygen uptake by isolated brown adipocytes stimulated by dopamine ( $50 \mu \mathrm{M})$ and norepinephrine $(0.2 \mu \mathrm{M})$ was determined in the presence of various concentrations of $d l$-propranolol. The catecholamines and various amounts of the antagonist were simultaneously added in the respiratory chamber. The maximal respiration rate duing the time interval between 1.5 to $3 \mathrm{~min}$ after the addition of the drugs was calculated. Data are presented as percentages of the value obtained in the absence of the antagonist, each value representing the mean $\pm \mathrm{SE}$ of 4 to 5 different cell preparations. Open circles indicate the basal rate of oxygen uptake measured in the absence of catecholamines.

brown adipocytes.

Norepinephrine appears to stimulate brown adipocytes primarily via its interaction with a $\beta$-adrenoreceptor. ${ }^{5,6)}$ As expected, a specific $\beta$-adrenergic antagonist, propranolol, $, 5,6,15$ ) reduced the respiration of brown adipocytes stimulated by $0.2 \mu \mathrm{M}$ norepinephrine (Fig. 4B). Propranolol, at a concentration about 50 times higher than that of the catecholamine that was simultaneously added, suppressed the respiration rate to the basal level. Propranolol was found to be very potent for suppressing the brown adipocyte respiration stimulated by dopamine (Fig. 4A). As little as $0.01 \mu \mathrm{M}$ of propranolol detectably suppressed dopamine-stimulated $(50 \mu \mathrm{M})$ respiration. Propranolol progressively suppressed respiration with increasing concentration, and a blocker concentration one-tenth that of dopamine was found to be enough to reduce respiration to the basal level. Phenoxybenzamine, an $\alpha$-adrenergic antagonist, ${ }^{5,6,8,9)}$ at up to $100 \mu \mathrm{M}$, failed to inhibit the respiration stimulated by either of the catecholamines (data not shown).

To test whether the inhibitory ability of haloperidol and propranolol was actually me-
TABle I. Respiratory Responses of Brown ADIPOCYTES TO DOPAMINE, NOREPINEPHRINE AND THE DOPAMINERgIC ANTAgonist, HALOPERIDOL

\begin{tabular}{lc} 
Addition & $\begin{array}{c}\text { Oxygen uptake } \\
(\mathrm{nmol} / \mathrm{min} / \mathrm{mg} \text { tissue })\end{array}$ \\
\hline None & $7.82 \pm 1.99$ \\
DA $(50 \mu \mathrm{M})$ & $29.6 \pm 3.6$ \\
NE $(0.2 \mu \mathrm{M})$ & $32.4 \pm 4.5$ \\
DA $(50 \mu \mathrm{M})+\mathrm{HP}(20 \mu \mathrm{M})$ & $15.0 \pm 2.0$ \\
NE $(0.2 \mu \mathrm{M})+\mathrm{HP}(20 \mu \mathrm{M})$ & $16.8 \pm 2.3$ \\
DA $(500 \mu \mathrm{M})+\mathrm{HP}(20 \mu \mathrm{M})$ & $16.9 \pm 2.3$ \\
NE $(2 \mu \mathrm{M})+\mathrm{HP}(20 \mu \mathrm{M})$ & $16.4 \pm 2.5$ \\
\hline
\end{tabular}

Each value represents the mean \pm SE of 3 different cell preparations. The catecholamines and propranolol were added to the respiratory chamber at the concentrations indicated in parentheses. Abbreviations used: DA, dopamine; NE, norepinephrine; HP, haloperidol.

diated through the interaction with a specific catecholamine receptor, the following experiments were carried out. The respiration of brown adipocytes was stimulated to a maximum level by either $0.2 \mu \mathrm{M}$ norepinephrine or by $50 \mu \mathrm{M}$ dopamine (Table I). The inclusion of $20 \mu \mathrm{M}$ haloperidol suppressed the level to approximately one-half that observed without the blocker. Even when the concentration of 
TABLE II. RESPIRATORY RESPONSES OF BROWN ADIPOCYTES TO DOPAMINE, NOREPINEPHRINE AND THE $\beta$-ADRENERGIC ANTAGONIST, PROPRANOLOL

\begin{tabular}{lc}
\hline Addition & $\begin{array}{c}\text { Oxygen uptake } \\
(\mathrm{nmol} / \mathrm{min} / \mathrm{mg} \text { tissue })\end{array}$ \\
\hline None & $7.46 \pm 1.44$ \\
$\mathrm{DA}(50 \mu \mathrm{M})$ & $27.1 \pm 3.2$ \\
$\mathrm{NE}(0.2 \mu \mathrm{M})$ & $28.4 \pm 4.2$ \\
$\mathrm{DA}(50 \mu \mathrm{M})+\mathrm{PP}(0.1 \mu \mathrm{M})$ & $13.9 \pm 5.6$ \\
$\mathrm{NE}(0.2 \mu \mathrm{M})+\mathrm{PP}(2 \mu \mathrm{M})$ & $15.8 \pm 1.6$ \\
$\mathrm{DA}(500 \mu \mathrm{M})+\mathrm{PP}(0.1 \mu \mathrm{M})$ & $30.8+5.2$ \\
$\mathrm{NE}(2 \mu \mathrm{M})+\mathrm{PP}(2 \mu \mathrm{M})$ & $29.8 \pm 3.6$ \\
\hline
\end{tabular}

Each value represents the mean \pm SE of 3 different cell preparations. The catecholamines and propranolol were added to the respiratory chamber at the concentrations indicated in parentheses. Abbreviations used: DA, dopamine; NE, norepinephrine; PP, propranolol.

dopamine and norepinephrine was each increased 10 fold, haloperidol still exerted an inhibitory action. In the next trial, a similar type of experiment was done with propranolol (Table II). In contrast to the case of haloperidol, an increased concentration of both catecholamines fully restored brown adipocyte respiration to the levels observable without the blocker. Finally, apomorphine, a dopaminergic agonist, ${ }^{18}$ when added at a concentration of $50 \mu \mathrm{M}$ was not found to exert any stimulative effect on the respiration of brown adipocyte (data not shown).

\section{DISCUSSION}

Calorigenesis of brown adipose tissue has been considered to be regulated primarily by norepinephrine that is released from the sympathetic nerve innervated in the tissue. Extensive studies by Bukowiecki et al. ${ }^{5)}$ on rat brown adipocytes have revealed that norepinephrine primarily exerts its calorigenic action through its interaction with the $\beta$-adrenoreceptor of the $\beta_{1}$-subtype. Although participation of the $\alpha$-adrenoreceptor in norepinephrinestimulated calorigenesis can be anticipated in the brown adipose tissue of rats, ${ }^{7 \sim 9)}$ the $\alpha$ adrenergic mechanism has only been confirmed in the isolated brown adipocytes from hamsters, ${ }^{19)}$ but not from rats. ${ }^{5,6)}$ Consistent with the observation by Bukowiecki et al.,5) phenoxybenzamine, an $\alpha$-adrenergic antagonist, in no way exerted any detectable effect on the norepinephrine-stimulated respiration in rat brown adipocytes in the present study (data not shown).

Rothwell et al. ${ }^{10)}$ found that dopamine was as effective as norepinephrine for stimulating thermogenesis when administered subcutaneously to rats. Increased thermogenesis by the catecholamine was suppressed by an antagonist of dopamine, pimozide, suggesting the involvement of a dopamine receptor in this particular event. Although the release of dopamine from synapse was very low, they suggested that dopamine may be important in the long-term regulation of thermogenesis. In agreement with their results obtained in vivo, dopamine stimulated the respiration by isolated cells from brown adipose tissue (Figs. 1 and 2). The respiratory response to dopamine was rapid, as was the case with norepinephrine (Fig. 1), and dopamine apparently stimulated lipolysis, suggesting that dopamine per se, but not the metabolite(s) stimulated brown adipocytes through its interaction with the catecholamine receptor and the subsequent enhancement of lypolysis.

As the physiological significance of dopamine stimulation of brown adipocytes at such an unexpected concentration (Fig. 2) appeared somewhat questionable, experiments were carried out to clarify which of the catecholamine receptors was actually responsible for this pheonomenon. Haloperidol has been shown as a specific and potent dopaminergic antagonist, which, when added at a concentration one-tenth that of dopamine, could fully counteract the dopamine action in rat anterior pituitary cells. ${ }^{17)}$ Although haloperidol added at relatively high concentrations exerted an inhibitory action on the dopamine-stimulated respiration of brown adipocytes, it also counteracted the norepinephrine action in the present study. (Fig. 3 and Table I). Thus, the diagnostic value of haloperidol for the dopaminergic system, 
at least in brown adipocytes, appeares to be limited. As both dopamine and norepinephrine did not overcome the inhibitory action of haloperidol, even at the very high concentrations (Table I), the blocker presumably suppressed brown adipocyte respiration through a nonspecific process that was independent of the specific catecholamine receptor. Also, treatment with $50 \mu \mathrm{M}$ apomorphine, a dopaminergic agonist which has exerted maximal biological effect at a concentration as low as $0.01 \mu \mathrm{M}$ in other dopaminergic systems, ${ }^{17,18)}$ did not stimulate the respiration of brown adipocytes (data not shown). Thus, the attempts to identify the dopamine receptor in isolated adipocytes were all unsuccessful. Alternatively, the observations that the specific $\beta$-adrenergic antagonist was effective for suppressing dopaminestimulated respiration (Fig. 4), and that the increasing concentration of the catecholamine overcame the inhibitory action of the blocker (Table II) both indicate that dopamine acted as a weak agonist of the $\beta$-adrenoreceptor to enhance the respiration of brown adipocytes. An antagonist of the $\beta$-adrenoreceptor, propranolol, that was employed in the present study in no way interfered with the binding of a specific dopaminergic agonist, dihydroergocryptine, to the dopamine receptor in bovine anterior pituitary membranes, even at concentrations higher than $0.1 \mathrm{~mm}^{17 \text { ) }}$ As there is evidence to indicate the existence of the dopamine receptor in brown adipose tissue, ${ }^{10,20)}$ studies with various dopaminergic antagonists or agonists in addition to those used currently would be needed before any definite conclusion can be drawn.

The cause of the different responses between intact animals and isolated brown adipocytes is not clear at present. Dopamine may exert its calorigenic action in vivo after being converted to other functional catecholamine(s). In this context, Rothwell et al. ${ }^{10)}$ indicated that propranolol, an antagonist of the $\beta$-adrenoreceptor, as well as pimozide, an antagonist of dopamine, were both equally effective for suppressing the respiration of dopamine-treated animals. There is also the possibility that dopamine enhanced heat production in the tissue other than brown adipose tissue such as liver through its interaction with the dopamine receptor. ${ }^{21,22)}$ The possibility that the functional catecholamine receptors including the dopamine receptor were damaged or lost during the course of cell isolation can not be ruled out.

In conclusion, dopamine at relatively high concentrations was found to stimulate the respiration of isolated brown adipocytes. However, no conclusive evidence supporting the involvement of the dopamine receptor in this process was obtained. Rather, dopamine appeared to stimulate the brown adipocytes through its interaction with the $\beta$-adrenoreceptor.

\section{REFERENCES}

1) D. G. Nicholis and R. M. Locke, Physiol. Rev., 64, 1 (1984).

2) E. Jequier and Y. Schutz, Int. J. Obesity, 9, suppl. 2, 1 (1985).

3) M. J. Stock and N. J. Rothwell, Int. J. Obesity, 9, suppl. 2, 9 (1985).

4) M. J. Stock and N. J. Rothwell, Biochem. Soc. Transac., 14, 239 (1986).

5) L. J. Bukowiecki, N. Folléa, A. Paradis and A. Collet, Am. J. Physiol., 238, E552 (1980).

6) B. E. Levin, K. Comai, R. A. O'Brien and A. C. Sullivan, Am. J. Physiol., 243, E217 (1982).

7) J. R. S. Arch, B. J. Brooks, P. L. Thully and S. Wilson, Biochem. Soc. Transac., 14, 230 (1980).

8) D. O. Foster, Int. J. Obesity, 9, suppl. 2, 25 (1985).

9) E. Nánberg and J. Putney, Jr., FEBS Lett., 195, 319 (1986).

10) N. J. Rothwell, M. J. Stock and M. G. Wyllie, Eur. J. Pharmacol., 77, 45 (1982).

11) T. Yonetani and G. S. Ray, J. Biol. Chem., 240, 3392 (1965).

12) S. B. Prusiner, B. Canon and O. Lindberg, Eur. J. Biochem., 6, 15 (1968).

13) L. B. Bieber, B. Petterson and O. Lindberg, Eur. J. Biochem., 58, 375 (1975).

14) B. Petterson, Eur. J. Biochem., 72, 235 (1977).

15) L. J. Bukowiecki, N, Folléa, J. Lupien and A. Paradis, J. Biol. Chem., 256, 12840 (1981).

16) G. Laurell and G. Tipping, Clin. Chim. Acta, 13, 317 (1966).

17) M. G. Caron, M. Beaulieu, V. Raymond, B. Gangnen, J. Drouin, R. J. Lefkowitz and F. Labrie, 
J. Biol. Chem., 253, 2244 (1978).

18) J. Arnt, A.V. Christensen and J. Hyttel, Neuropharmacol., 20, 1331 (1981).

19) R. J. Schimmel, L. McCarthy and K. K. McMahon, Am. J. Physiol., 244, C362 (1983).

20) N. J. Rothwell and M. J. Stock, Pflügers Arch., 398,
327 (1981).

21) M. N. Berry, D. G. Clark, A. R. Grivell and P. G. Wallace, Eur. J. Biochem., 131, 215 (1983).

22) M. N. Berry, D. G. Clark, A. R. Grivell and P. G. Wallace, Metabolism, 34, 141 (1985). 